\title{
MEDIA BIMBINGAN KARIR CERITA BERGAMBAR UNTUK MENUMBUHKAN KESADARAN KARIR ANAK USIA DINI
}

\author{
Dinar Mahdalena Leksana ${ }^{\text {a, } 1}$ \\ ${ }^{a}$ Universitas Islam Lamongan, Indonesia \\ 1 chealeksa.ca@gmail.com;
}

\begin{tabular}{l}
\hline Informasi artikel \\
\hline Received : \\
Februari 7, 2020. \\
Revised : \\
Februari 26, 2020. \\
Publish : \\
Maret 07, 2020. \\
Kata kunci: \\
Media Bimbingan; \\
Kesdaran Karir; \\
Anak Usia Dini
\end{tabular}

Keywords:

Guidance Media;

Caree Awarness;

Childhood

\begin{abstract}
ABSTRAK
Peneltian ini termasuk dalam jenis penelitian kuantitatif yang bertujuan untuk mengetahui pengaruh dari media bimbingan karir buku cerita bergambar, dalam menumbuhkan kesadaran karir pada anak usia dini, penelitian ini dilatarbelakangi oleh tingkat kesadaran karir anak usia dini di PAUD Bunga Harapan I Lamongan yang bisa dikatakan masih kurang, dan keterbatasan media bimbingan yang ada di PAUD tersebut. Sehingga peneliti menaruh harapan besar bahwa buku cerita bergambar ini akan dapat menumbuhkan kesadaran karir mereka. Penelitian ini menggunakan desain quasi eksperimen kemudian dianalisis dengan taraf signifikasi $5 \%$ dengan uji wilcoxon yang dibantu dengan program software spss 21, Hipotesis pada penelitian ini diuji menggunakan uji independent sample $t$-test dengan bantuan SPSS for windows release 21, dengan tingkat signifikansinya terbesar 0,05 (5\%). Hasil yang diperoleh dari uji hipotesis tersebut adalah diperoleh significant (sig) sebesar 0,000 $<0,05$. Dengan demikian ada pengaruh hipotesis penelitian yang menyatakan bahwa media bimbingan karir cerita bergambar berpengaruh terhadap kesadaran karir anak di PAUD Bunga Harapan 1 Lamongan

ABSTRACT
This research is included in the type of quantitative research that aims to
determine the effect of the media career guidance picture book, in
fostering career awareness in early childhood, this research is motivated
by the level of early childhood career awareness in PAUD Bunga
Harapan I Lamongan which can be said to be still lacking, and the
limitations of the media of guidance in PAUD. So researchers have high
hopes that this picture book will be able to foster their career awareness.
This study used a quasi-experimental design and then analyzed with a
significance level of 5\% with the Wilcoxon test assisted with the SPSS
21 software program. The hypothesis in this study was tested using the
independent sample t-test with the help of SPSS for Windows Release
21 , with the greatest significance level of 0 , 05 (5\%). The results
obtained from the hypothesis test are obtained significant (sig) of 0,000
$<0.05$. Thus there is the influence of the research hypothesis which states
that the pictorial story career guidance media influences children's career
awareness in PAUD Bunga Harapan 1 Lamongan.
\end{abstract}

This work is licensed under a Creative Commons Attribution-ShareAlike 4.0 International License. Allows readers to read, download, copy, distribute, print, search, or link to the full texts of its articles and allow readers to use them for any other lawful purpose. 


\section{PENDAHULUAN}

Penelitian ini dilatar belakangi oleh, tingkat kesadaran karir dari anak-anak usia dini yang ada di PAUD Bunga Harapan 1 Lamongan masih dapat dikatakan rendah, hal ini dilihat dari sikap anak-anak yang belum memahami akan jenis-jenis tugas-tugas dari beberapa profesi pekerjaan yang ada disekitar mereka, hal ini diketahui dari hasil wawancara yang dilakukan oleh peneliti diawal penelitian.

Pada anak usia dini, kesadaran karir lebih dititik beratkan pada eksplorasi karir dan pengenalan jabatan yang ada dalam lingkungan masyarakat. Anak belum sampai pada tahap pemlihan karir, namun pemilihan karir sangat dipengaruhi oleh lingkungan keluarga, masyarakat, media, atau faktor lain yang ikut membantu dalam membuat keputusan karir, sehingga diperlukan kesadaran karir sejak dini.

Konteks penelitian ini adalah menindak lanjuti dari kegiatan penelitian sebelumnya yang mendisain media bimbingan karir untuk anak usia dini dengan buku cerita bergambar, dalam penelitian ini bertujuan untuk meneliti bagaimana pengaruh media bimbingan karir tersebut terhadap kesadaran karir anak usia dini.

Seperti yang dikatakan dalam hasil penelitian (Gysbers, 2005) menyatakan bahwa pelaksanaan bimbingan konseling terpadu di sekolah dikatakan penting. Bimbingan karir yang dilakukan merujuk pada model bimbingan komprehensif. Alasan model ini cocok dilaksanakan karena terbukti anak lebih dapat memahami diri dan mampu merencanakan karir pada masa yang akan datang. Diperkuat oleh penelitian (Sheldon \& Morgan, 1984) mengemukakan bahwa bimbingan karir disekolah terbukti mampu meningkatkan prestasi belajar anak dan konsep diri yang positif serta memiliki pandangan yang jauh mengenai masa depan. Melihat begitu pentingnya bimbingan karir dilaksanakan, maka peneliti ingin mengetahui bagaimana pengaruh, media bimbingan karir cerita bergambar terhadap kesadaran karir anak, di PAUD Bunga Harapan I Lamongan.

\section{Bimbingan Karier Anak Usia Dini}

Bimbingan dan konseling anak usia dini adalah proses pemberian bantuan kepada anak usia dini yang dilakukan oleh pendidik (guru/pendamping) agar anak dapat tumbuh dan berkembang secara optimal serta memiliki kemampuan mengatasi 
/ menyelesaikan permasalahan-permasalahan yang dihadapinya juga memaparkan bahwa ruang lingkup bimbingan dan konseling pada anak usia dini yaitu; bimbingan pribadi-sosial; bimbingan belajar; bimbingan karir.

Bimbingan karir adalah suatu upaya bantuan terhadap peserta didik agar dapat mengenal dan memahami dirinya, mengenal dunia kerjanya, mengembangkan masa depan sesuai dengan bentuk kehidupan yang diharapkannya, mampu menentukan dan mengambil keputusan secara tepat dan bertanggungjawab.

Bimbingan karir juga merupakan salah satu bidang dalam bimbingan dan konseling yang ada di sekolah-sekolah. Menurut (Winkel, 2005) bimbingan karir adalah bimbingan dalam mempersiapkan diri menghadapi dunia kerja, dalam memilih lapangan kerja atau jabatan /profesi tertentu serta membekali diri supaya siap memangku jabatan itu, dan dalam menyesuaikan diri dengan berbagai tuntutan dari lapanan pekerjaan yang dimasuki. Bimbingan karir juga dapat dipakai sebagai sarana pemenuhan kebutuhan perkembangan peserta didik yang harus dilihat sebagai bagaian integral dari program pendidikan yang diintegrasikan dalam setiap pengalaman belajar bidang studi.

Bimbingan Karier, yaitu bidang pelayanan yang membantu peserta didik dalam memahami dan menilai informasi, serta memilih dan mengambil keputusan karier. Bidang ini bertujuan membantu peserta didik mengenal dunia kerja agar dapat menentukan kemana selanjutnya mereka akan melangkah setelah lulus dan mengetahui potensi diri yang dimiliki agar dapat diterapkan dengan kehidupannya serta dapat membaca peluang karir yang tersedia di lingkungan sekitarnya.

Pelayanan bimbingan dan konseling membantu siswa Anak usia dini mengenali dan mulai mengarahkan diri untuk masa depan karier. Bidang bimbingan ini memuat pokok-pokok materi berikut:

1. Pengenalan awal terhadap dunia kerja dan usaha memperoleh penghasilan untuk memenuhi kebutuhan hidup.

2. Pengenalan, orientasi dan informasi karier pada umumnya secara sederhana. 
3. Pengenalan dan pemahaman diri secara awal berkenaan dengan kecenderungan karier yang hendak dikembangkan.

Orientasi dan informasi sederhana terhadap pendidikan yang lebih tinggi, khususnya dalam kaitannya dengan karier yang hendak dikembangkan.

Pemberian materi bimbingan karier untuk siswa-siswa paud pada umumnya dimaksudkan untuk:

1. Mengembangkan sikap positif terhadap segala jenis pekerjaan.

2. Membawa para siswa untuk menyadari betapa luasnya dunia kerja yang ada.

3. Menekankan jasa dari masing-masing jenis pekerjaan.

\section{Cerita Anak dan Cerita Bergambar}

Cerita (sastra) anak biasanya didefinisikan sebagai cerita untuk anak (Winch, 2006; Obi, 2010). Dengan demikian, semua hal yang dikisahkan dalam cerita, baik budaya, ideologi cerita dibuat untuk anak. (Winch, 2006) menyatakan bahwa cerita anak biasanya ditulis oleh orang dewasa diperuntukkan kepada anak. Cerita anak dibuat untuk mengajarkan dan menyebarkan nilai-nilai agama, moral, dan pendidikan.

Cerita anak biasanya berbentuk prosa, seperti cerpen, novel, walaupun juga ada dalam bentuk puisi dan drama. Cerita anak memiliki beberapa ciri. Pertama, Sastra anak menampilkan anak sebagai pahlawan (tokoh hero). Kedua, Ide atau pemikiran, hubungan unsur didalamnya, dan bahasa yang digunakan sederhana. Ketiga, Sastra anak memiliki tujuan untuk mengajarkan moral (Sutherland, 1985). Cerita (sastra) anak merefleksikan pandangan-pandangan dan asumsi-asumsi tentang kemanusiaan, organisasi sosial, tata perilaku, prinsip moral, dan hal-hal yang penting dalam kehidupan yang diangkat oleh pengarang (Obi, 2010).

Di dalam Kamus Besar Bahasa Indonesia adalah tuntan yang membentangkan bagaimana terjadinya suatu hal (peristiwa, kejadian dan sebagainya). Karangan yang menuturkan perbuatan, pengalaman, atau penderitaan orang dan sebagainya (baik yang sungguh-sungguh terjadi maupun yang hanya rekaan belaka). Lakon yang diwujudkan atau dipertunjukkan di film (sandiwara, wayang dan sebagainya). Omong kosong dongeng (yang tidak benar). Sedangkan gambar menurut Kaus Besar 
Bahasa Indonesia "gambar adalah tiruan barang (orang atau binatang, tumbuhan dan sebagainya) yang dibuat dengan coretan dengan pensil dan sebgainjadi dapat disimpulkan cerita bergambar adalah karangan yang munuturkan perbuatan, pengalaman, atau penderitaan orang tentang suatu jkejadian atau peristiwa, dan sebagainya yang disertai dengan gambar.

\section{METODE}

Jenis Penelitian yang digunakan dalam penelitian ini adalah metode quasi eksperimen dengan pendekatan kuantitatif. Menggunakan metode quasi eksperimen karena penelitian ini merupakan kegiatan sehari-hari dalam proses belajar mengajar yang tidak mungkin untuk mengontrol semua variable yang mempengaruhi variable bebas dan terikat secara ketat. Penelitian ini menggunakan pendekatan penelitian kuantitatif yaitu metode kuasi eksperimen dengan desain penelitian yang digunakan (nonequivalent control groups design) pada anak TK A1 dan Kelompok TK A2 di PAUD Bunga Harapan 1 Lamongan.

Penelitian kuasi eksperimen dengan desain Non-equivalent pretest post test control group design melibatkan dua kelompok yaitu kelompok eksperimen dan kelompok kontrol. Hal ini sesuai dengan pendapat Creswell dalam Sugiono, yang menyatakan bahwa peneliti dalam quasi eksperimen ini menggunakan kelompok kontrol dan kelompok eksperimen tetapi tidak secara acak dalam memasukkan sampling ke dalam dua kelompok tersebut.

Dalam penelitian ini Kelompok TK A1 sebagai kelompok kontrol dan Kelompok TK A2 sebagai kelompok eksperimen dengan desain pre-test dan posttest, sebelum diberi perlakuan kelompok diberi pretest dengan maksud untuk mengetahui keadaan awal apakah ada perbedaan antara kelompok eksperimen dengan kelompok kontrol.

Hasil pre-test yang baik bila nilai kelompok eksperimen tidak berbeda secara signifikan dengan kelompok kontrol. Pengaruh perlakuan adalah (O2 - O1) - (O4 O3). Desain digambarkan sebagai berikut: 
Gambar. 3.1

Desain Jenis penelitian

$$
\begin{array}{llll}
\text { A } & \text { O1 } & \text { X1 } & \text { O2 } \\
\text { B } & \text { O3 } & \text { X2 } & \text { O4 }
\end{array}
$$

Keterangan:
$\mathrm{A} \quad=$ Kelompok Eksperimen
$\mathrm{B} \quad=$ Kelompok Kontrol
O1 = Pretes sebelum diberikan perlakuan pada kelompok eksperiment
O2 = Postes setelah diberikan perlakuan pada kelompok eksperimen.

$\mathrm{X} 1=$ =Perlakuan menggunakan media bimbingan karir cerita bergambar

$\mathrm{X} 2=$ Tidak mendapatkan perlakuan kontrol

$\mathrm{O} 3=$ Pretes pada kelompok kontrol

$\mathrm{O} 4=$ Postes pada kelompok control

Berdasarkan gambar di atas, kedua kelompok tersebut diberikan pretest dan posttest, tetapi dibedakan dalam memberikan perlakuan. Pada kelompok eksperimen diberi perlakuan dengan menggunakan media audiovisual, sedangkan pada kelompok kontrol tanpa menggunakan perlakuan. Tahap - tahap yang dilakukan dalam penelitian ini yaitu: yang pertama;Tahap pemberian tes awal ( pretest).

Pada tahap ini kedua kelompok baik kelompok eksperimen maupun kelompok kontrol diberi pretest berupa tes lisan sebelum diberikan perlakuan (treatment). Pretest dilakukan untuk membuktikan bahwa kelompok eksperimen maupun kelompok kontrol memiliki kemampuan yang sama dalam kesdaran karir mereka. Tes ini bertujuan untuk mengetahui keadaan awal dari kedua kelompok tersebut. Apabila hasil dari pretest menunjukan hasil yang tidak signifikan, maka penelitian dapat dilanjutkan ke tahap selanjunya yaitu menggunakan media bimbingan karir cerita bergambar.

Pada tahap ke dua yaitu tahap pemberian perlakuan (treatment). Memberikan perlakuan (treatment) pada kelompok eksperimen berupa pemberian perlakuan menggunakan media bimbingan karir cerita bergambar yang berisi 14 cerita dengan 
gambar ilustrasi sesuai deng cerita. Kegiatan dibagi dalam 7 sesi pertemuan, dalam tuap pertemuan di gunakan dua judul cerita profesi pekerjaan dalam proses pembelajaran untuk menumbuhkan kesadarn karir anak. Kelas kontrol tidak diberi perlakuan.

Tahap yang ketiga yaitu tahap pemberian tes akhir (posttest), dengan memberikan posttest kepada kelompok eksperimen setelah diberikan perlakuan dengan media bimbingan karir cerita bergambar, sedangkan pemberian posttest pada kelompok kontrol diberikan setelah pelaksanaan pretest karena tanpa adanya perlakuan. Hal ini dilakukan untuk mengetahui pengaruh pemberian perlakuan (treatment) terhadap kelompok eksperimen. Hasil dari tes ini dibandingkan dengan hasil dari tes awal yang telah diberikan sebelumnya.

\section{PEMBAHASAN}

Hasil Hipotesis pada penelitian ini perlu diuji untuk membuktikan kebenaran dari hipotesis yang telah dirumuskan sebelumnya. Dalam pengujian hipotesis ini peneliti menggunakan uji independent sample t-test dengan bantuan SPSS for windows release 21 . Uji independent sample t-test adalah uji hipotesis ini digunakan untuk membandingkan rata-rata dari dua grup yang tidak berhubungan satu dengan yang lain, dengan tujuan apakah kedua grup tersebut mempunyai rata-rata yang sama atau tidak. Dalam penelitian ini tingkat signifikansinya terbesar 0,05 (5\%). Adapun perhitungan Uji Independen sample $t$-test ini bisa dilihat pada Tabel dibawah ini:

\section{Tabel 1.}

Output Hasil Perhitungan Uji Independen Sample t-test

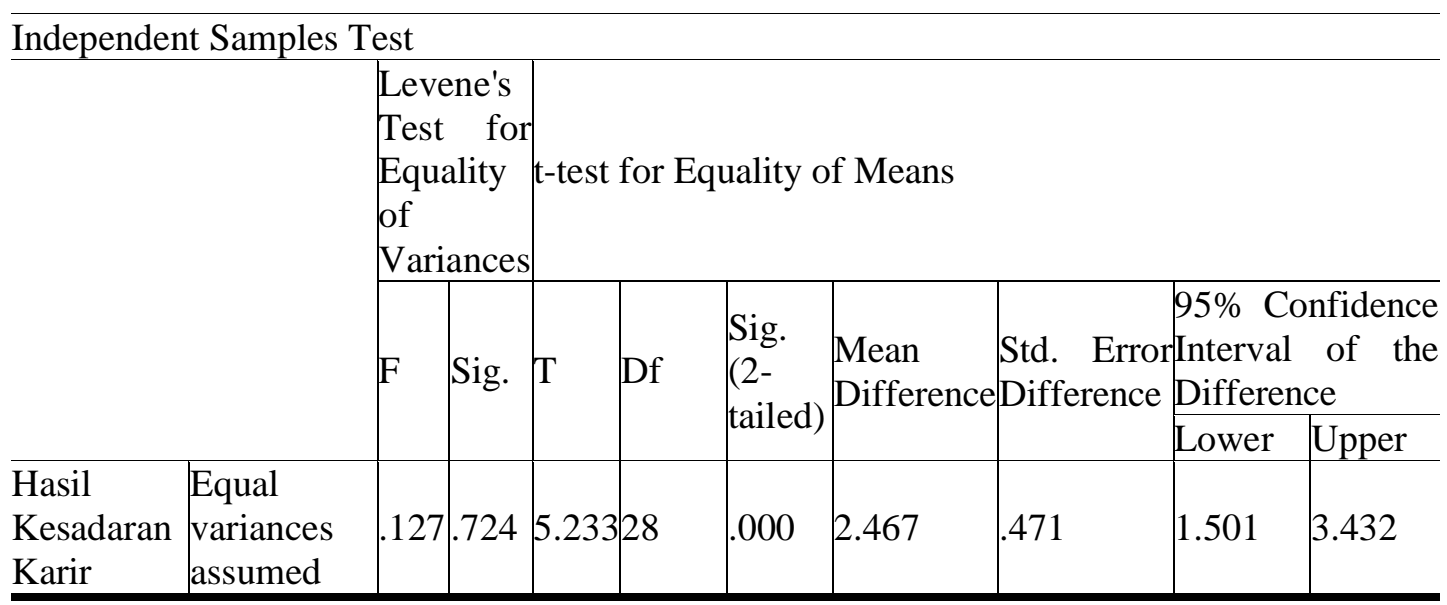




\begin{tabular}{l|l|l|l|l|l|l|l|l|l|l}
\hline $\begin{array}{l}\text { Equal } \\
\text { variances } \\
\text { not } \\
\text { assumed }\end{array}$ & & & 5.233 & 27.707 & 000 & 2.467 & .471 & 1.501 & 3.433 \\
\hline
\end{tabular}

Tabel 2

Output HasilPerhitungan Statistik Deskriptif Hasil Kesadaran Karir Eksperimen dan Kontrol

\begin{tabular}{|c|c|c|c|c|c|}
\hline \multicolumn{6}{|c|}{ Group Statistics } \\
\hline & Kelas & $\mathrm{N}$ & Mean & Std. Deviation & $\begin{array}{l}\text { Std. Error } \\
\text { Mean }\end{array}$ \\
\hline $\begin{array}{l}\text { Hasil } \\
\text { Kesadaran }\end{array}$ & $\begin{array}{l}\text { Post-Test Kelas } \\
\text { Ekperimen }\end{array}$ & 15 & 16.93 & 1.223 & 316 \\
\hline Karir anak & $\begin{array}{l}\text { Post-Test Kelas } \\
\text { Kontrol }\end{array}$ & 15 & 14.47 & 1.356 & .350 \\
\hline
\end{tabular}

Gambar 1

Grafik Perbedaan Hasil Perlakuan

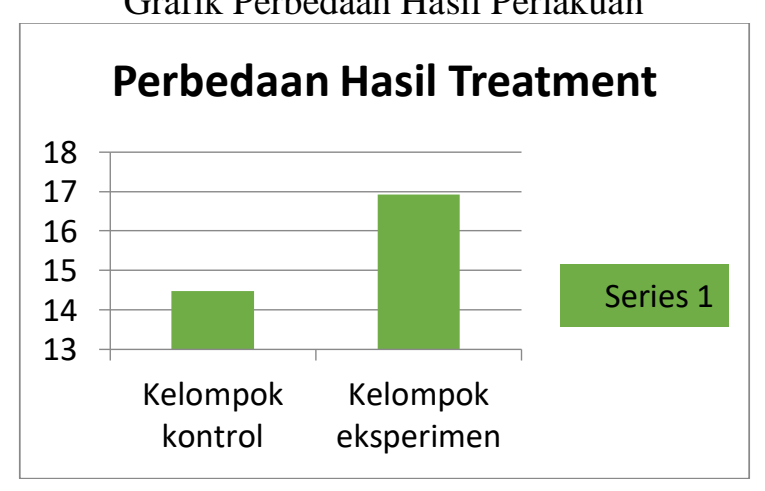

\section{KESIMPULAN}

Pada tabel 1 Menunjukkan bahwa output diperoleh significant (sig) sebesar $0,000<0,05$ maka dapat disimpulkan bahwa ada perbedaan rata-rata kesadaran karir anak antara kelompok eksperimen (media bimbingan karir cerita bergambar) dengan kelompok kontrol (tanpa perlakuan). Dan juga dapat dilihat ada tabel 2 pada hasil statistik deskriptif ada perbedaan nilai rata-rata posttest kesadaran karir anak antara kelompok eksperimen dengan kelompok kontrol yaitu kelompok eksperimen sebesar 16,93 sedangkan kelmpok kontrol 14,47. Dari hasil tersebut ini membuktikan bahwa ada perbedaan antara hasil kesadaran karir anak Kelompok TK PAUD Bunga Harapan I pada kelompok eksperimen dengan menggunakan media bimbingan karir cerita bergambar dengan hasil kesadaran karir anak pada kelompok kontrol tanpa perlakuan. 


\section{REFERENSI}

Departemen Pendidikan Nasional. (2008). Kamus Besar Bahasa Indonesia. Edisi ke-4. Jakarta: Gramedia Pustaka Utama

El Fiah, R. (2014). Mengembangkan Potensi Kecerdasan Spiritual Anak Usia Dini Implikasi Bimbingannya. Konseli: Jurnal Bimbingan dan Konseling, 1(2), https://doi.org/10.24042/kons.v1i2.1450

Gysbers, N.C., \& Henderson, P. (2000). Developing \& Managing Your School Guidance Program. Alexandria: American Counseling Association.

Gysbers, Norman C. (2005). Comprehensive School Guidance Programs in the United States: A Career Profile. International Journal For Educational and Vocational Guidance, 5, 203-2015, DOI 10.1007/s10775-005-8800-7

Hodges, Shannon, Kimber Shelton, Morgan Brooks, Michelle Lyn. (2016). The College and University Counseling Manual: https://books.google.co.id/books?id. Diakses pada 24 Februari 2019. Nigeria.

Obi, dkk. (2010). Children Literature. Nigeria: National Open University of

Sheldon, C., \& Morgan, C. D. (1984). The child development specialist: A prevention program. The Personnel and Guidance Journal, 62, 470-474, https://doi.org/10.1111/j.2164-4918.1984.tb00258.x

Sugiyono. (2016). Metode Penelitian Kuantitatif, Kualitatif, dan R\&D. Bandung: Alfabeta

Sutherland, Robert D. (1985). Hidden Persuaders: Political Ideologies in Literature for Children. Jurnal Children's Literature in Education, 16(3)

Winch, G., Johnston, R. R., March, P., Ljungdahl, L., \& Holliday, M. (2006). Literacy, Reading and Writing and Children Literature. Oxford: Oxford University Press.

Winkel.W.S. (2005). Bimbingan dan Konseling di Institusi Pendidikan. Yogyakarta: Media Abadi. 